Supporting Information

\title{
Non-ideal Cyclic Voltammetry of Redox Monolayers on Silicon Electrodes: Peak Splitting is Caused by Heterogeneous \\ Photocurrents and Not by Molecular Disorder
}

Song Zhang, Xin Lyu, Carlos Hurtado Torres, Nadim Darwish, Simone Ciampi*

School of Molecular and Life Sciences, Curtin University, Bentley, Western Australia 6102, Australia

Email: simone.ciampi@curtin.edu.au 
a

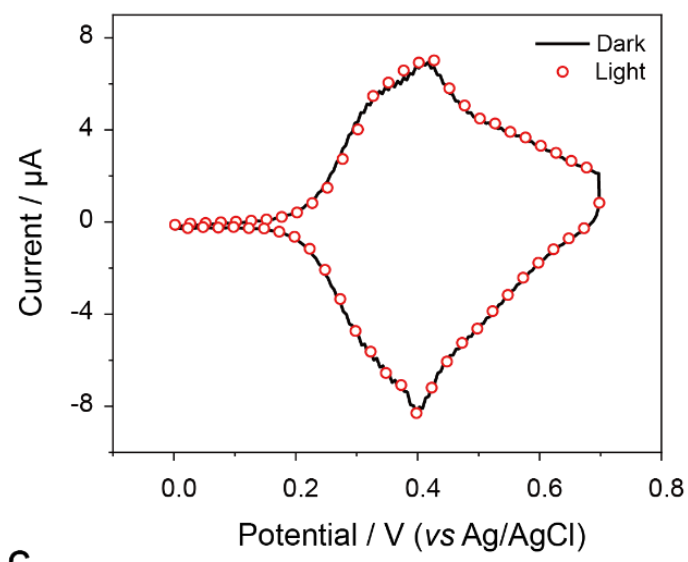

C

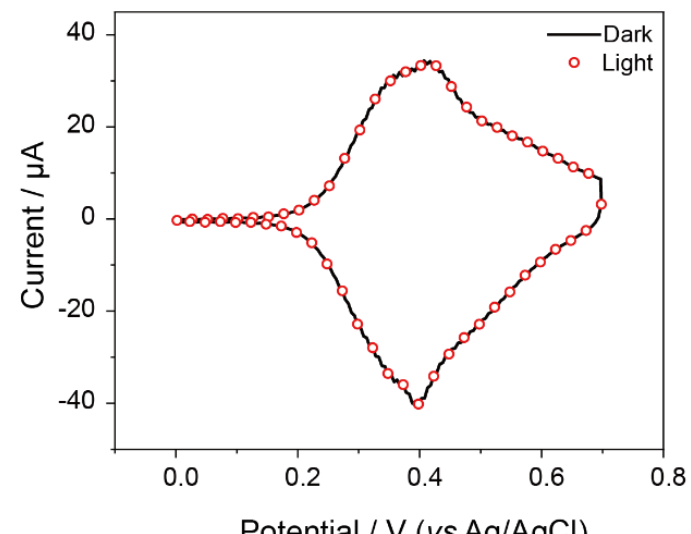

e

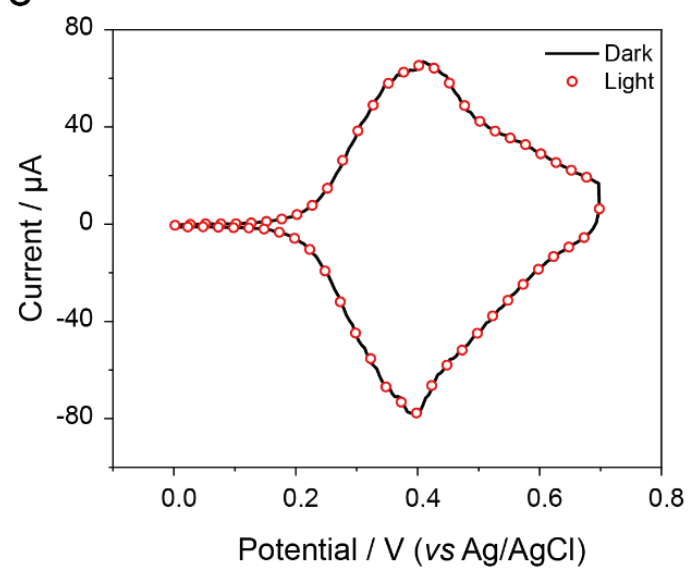

b

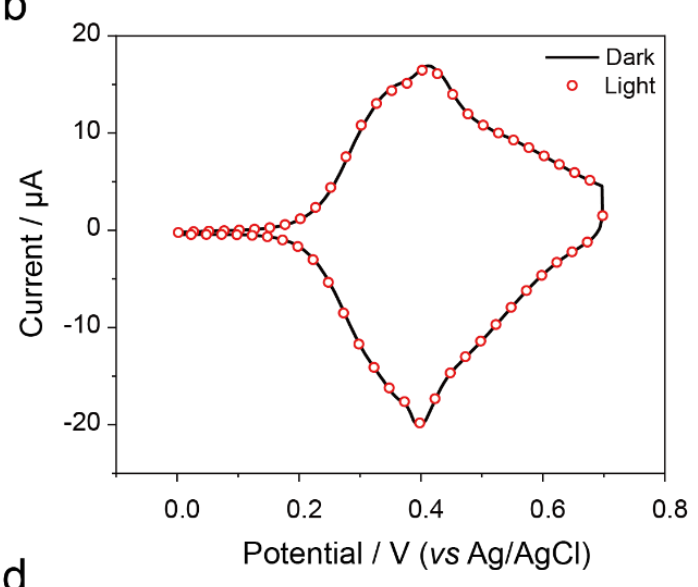

d
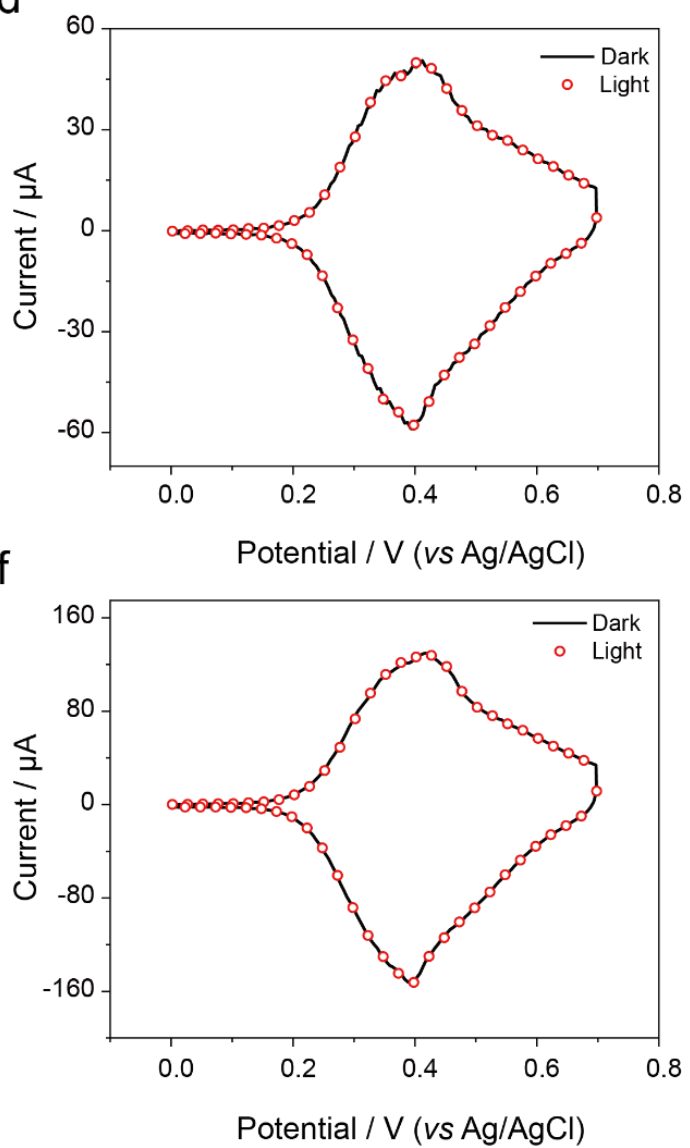

Figure S1. Representative CVs of a monolayer-modified gold electrode [11-ferrocenyl-1-undecanethiol monolayers self-assembled on $\mathrm{Au}(111)]$. The voltage sweep rate was changed between 100 and $2000 \mathrm{mV}$ $\mathrm{s}^{-1}$ and the data acquired in $1.0 \mathrm{M} \mathrm{HClO}_{4}$, either under dark or under electrode illumination (solid line, dark; state, red empty symbols, light). Electrode illumination had no effect on the CV traces: a) $100 \mathrm{mV} \mathrm{s}^{-1}$, dark coverage $=5.22 \times 10^{-10} \mathrm{~mol} \mathrm{~cm}$, coverage under light $=5.17 \times 10^{-10} \mathrm{~mol} \mathrm{~cm}^{-2}$; b) $250 \mathrm{mV} \mathrm{s}^{-1}$, dark coverage $=5.19 \times 10^{-10} \mathrm{~mol} \mathrm{~cm}^{-2}$, coverage under light $\left.=5.22 \times 10^{-10} \mathrm{~mol} \mathrm{~cm}^{-2} ; \mathrm{c}\right) 500 \mathrm{mV} \mathrm{s}$, dark coverage $=5.22 \times 10^{-10} \mathrm{~mol} \mathrm{~cm}{ }^{-2}$, coverage under light $=5.17 \times 10^{-10} \mathrm{~mol} \mathrm{~cm}^{-2} ;$ d) $750 \mathrm{mV} \mathrm{s}^{-1}$, dark coverage $=5.06 \times 10^{-10} \mathrm{~mol} \mathrm{~cm}^{-2}$, coverage under light $=5.08 \times 10^{-10} \mathrm{~mol} \mathrm{~cm}^{-2}$; e) $1000 \mathrm{mV} \mathrm{s}{ }^{-1}$, dark coverage $=5.12 \times 10^{-10} \mathrm{~mol} \mathrm{~cm} \mathrm{~cm}^{-2}$, coverage under light $\left.=5.11 \times 10^{-10} \mathrm{~mol} \mathrm{~cm}^{-2} ; \mathrm{f}\right) 2000 \mathrm{mV} \mathrm{s}$, dark coverage $=4.99 \times 10^{-10} \mathrm{~mol} \mathrm{~cm}^{-2}$, coverage under light $=4.97 \times 10^{-10} \mathrm{~mol} \mathrm{~cm}^{-2}$ ). 


\section{a}

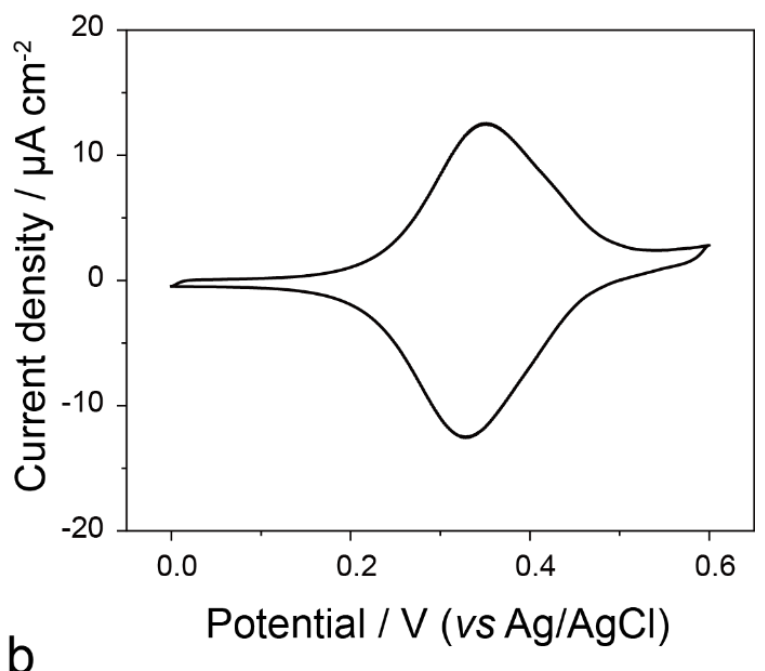

b
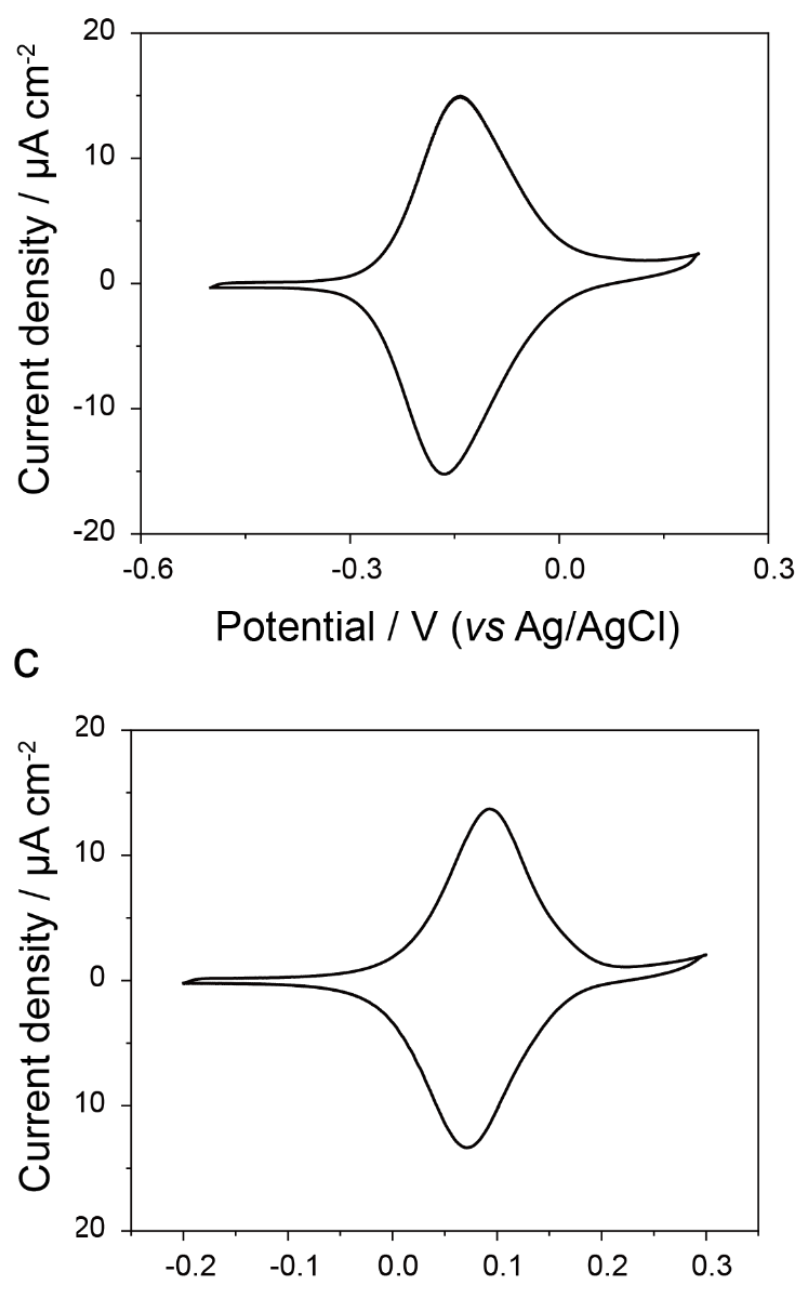

Potential / V (vs Ag/AgCl)

Figure S2. Representative CVs of M-2 samples prepared on either (a) HD p-type Si(111), dark, and indicating a ferrocene coverage of $1.94 \pm 0.26 \times 10^{-10} \mathrm{~mol} \mathrm{~cm}^{-2}$, (b) LD n-type Si(111) under light intensity $24.1 \mathrm{~mW} \mathrm{~cm}{ }^{-2}$, with a coverage of $1.99 \pm 0.84 \times 10^{-10} \mathrm{~mol} \mathrm{~cm}^{-2}$, and (c) LD n-type $\mathrm{Si}(100)$ under light intensity $24.1 \mathrm{~mW} \mathrm{~cm}{ }^{-2}$, with a coverage of $1.44 \pm 0.23 \times 10^{-10} \mathrm{~mol} \mathrm{~cm}^{-2}$. The electrolyte was aqueous $1.0 \mathrm{M} \mathrm{HClO}_{4}$, and the scan rate was $100 \mathrm{mV} \mathrm{s}^{-1}$. 


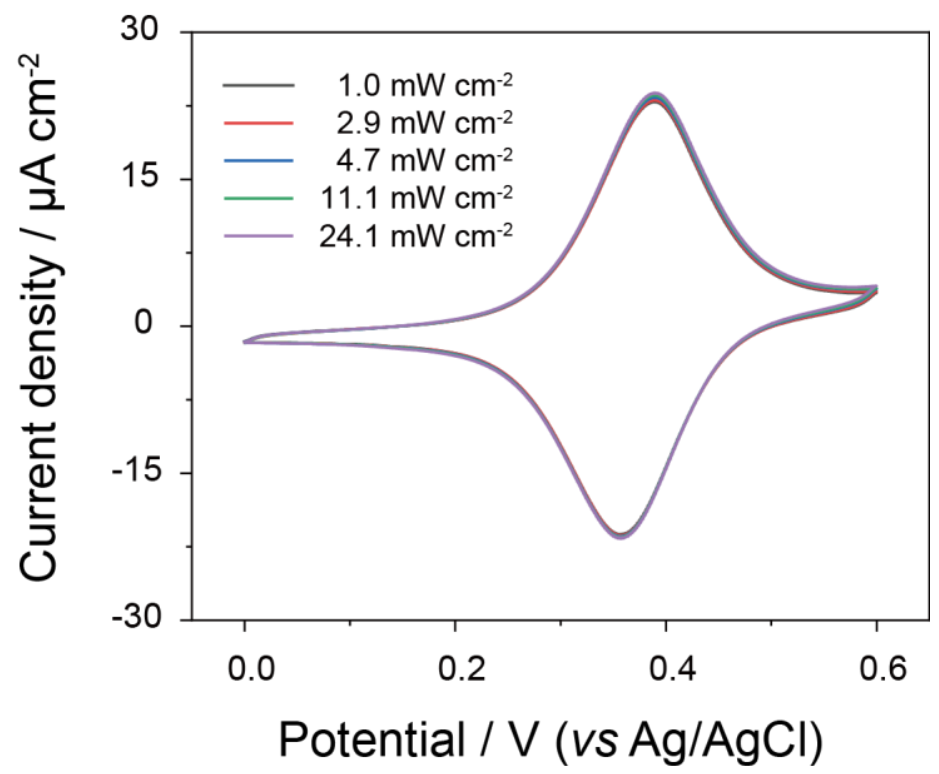

Figure S3. Representative CVs of an M-2 monolayer prepared on HD p-type $\mathrm{Si}(111)$ and recorded under different light intensities (indicated in figure). The electrolyte was aqueous $1.0 \mathrm{M} \mathrm{HClO}_{4}$, and the scan rate was $100 \mathrm{mV} \mathrm{s}^{-1}$.

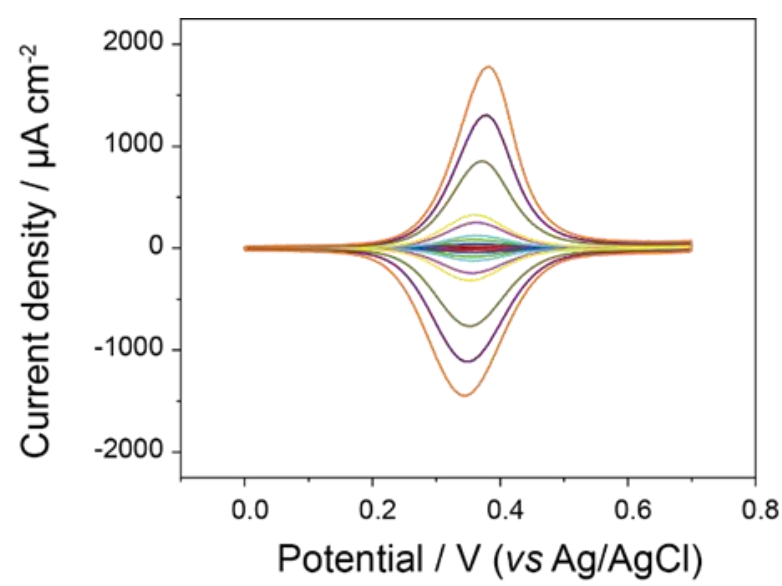

Figure S4. Representative CVs of an M-2 sample prepared on HD p-type Si(111) and recorded under dark at different voltage scan rates $\left(50 \mathrm{mV} \mathrm{s}^{-1}, 100 \mathrm{mV} \mathrm{s}^{-1}, 250 \mathrm{mV} \mathrm{s}^{-1}, 500 \mathrm{mV} \mathrm{s}^{-1}, 750 \mathrm{mV} \mathrm{s}^{-1}, 1.0\right.$ $\mathrm{V} \mathrm{s}^{-1}, 2.0 \mathrm{~V} \mathrm{~s}^{-1}, 5.0 \mathrm{~V} \mathrm{~s}^{-1}, 7.5 \mathrm{~V} \mathrm{~s}^{-1}, 10.0 \mathrm{~V} \mathrm{~s}^{-1}$ ). The electrolyte was aqueous $1.0 \mathrm{M} \mathrm{HClO}_{4}$. 


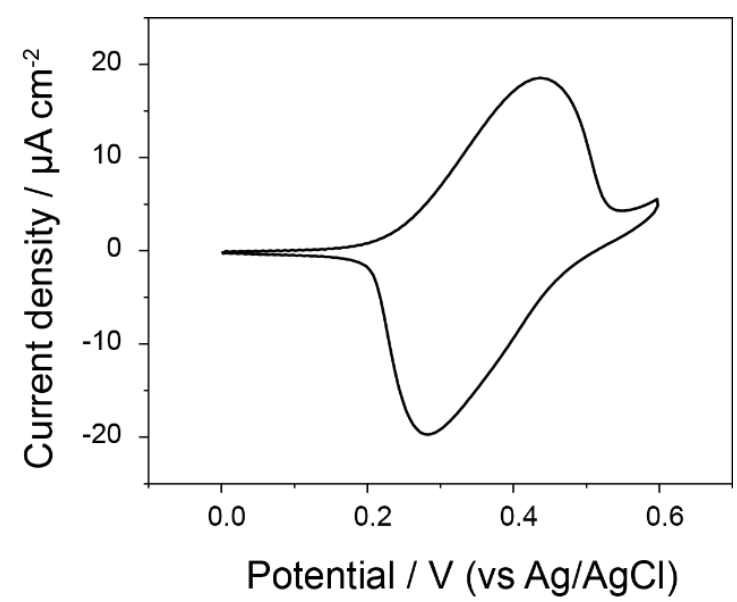

Figure S5. Representative CV of an M-2 sample prepared on LD n-type $\mathrm{Si}(111)$ and recorded under dark. The electrolyte was aqueous $1.0 \mathrm{M} \mathrm{HClO}_{4}$, and the scan rate was $100 \mathrm{mV} \mathrm{s}^{-1}$. 
a)

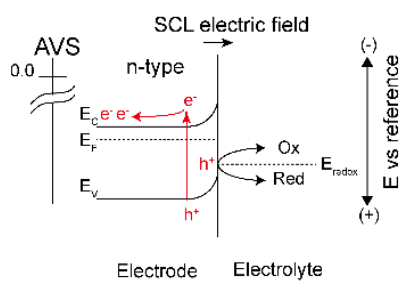

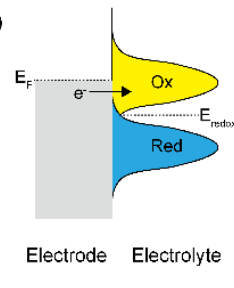

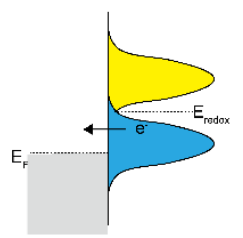

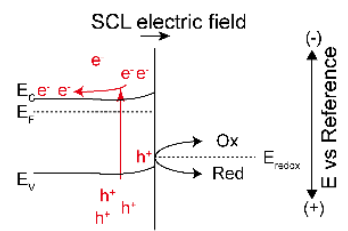

Figure S6. Energy-levels diagrams for redox chemistry at semiconductor photoanodes and metals. The general convention is to draw diagrams such band diagrams such that the energy of the system is lowered as electrons fall down toward the source of positive potential (i.e. drawn towards the bottom of the diagram). a) In n-type semiconductor electrodes, at potentials more positive than $\mathrm{E}_{\mathrm{FB}}$ (flat bands, situation not depicted here), the Fermi level $\left(\mathrm{E}_{\mathrm{F}}\right)$ is lowered (i.e. further away from the zero AVS, absolute vacuum scale, or towards more positive potentials against a reference) and electrons are forced away from the space charge region and leave behind ionized positively charged donor centers. In depletion, and under illumination, holes generated in the valence band will migrate toward the interface under a space-charge layer (SCL) electric field pointing outward (i.e. bands pointing upward) where this vacant state (the hole) at the top of the valence band will consume available electrons, that is, participate in redox reactions (i.e. photooxidations at n-type electrodes). Depleted n-type electrodes under illumination can therefore act as contra-thermodynamic photoanodes. In summary, the blocking effect of depleted dark silicon electrodes is efficiently reversed upon illumination with light of energy bigger than the band gap, provided that inversion is not reached and electron-hole recombination events are minimized. Since valence band holes mediate the oxidation of surface species, the potential at which the rate of change of surface concentrations peaks (i.e. a peak appears in the $\mathrm{CV}$ of non-diffusive species) is less positive (i.e. closer to the zero of the AVS scale), or in other words contra-thermodynamic relative to the bias required in a metal electrode. The situation of a metal electrode is depicted in b). Here the applied potential lifting or lowering $\mathrm{E}_{\mathrm{F}}$ above or below $\mathrm{E}_{\mathrm{redox}}$ corresponds to electro-reduction (left) and electro-oxidation (right). There is no gap hence no photoeffects (note that $\mathrm{e}^{-} / \mathrm{h}^{+}$forms also in metals but they recombine before they can be effectively put to use in driving surface reactions). c) In a semiconductor photoelectrode the effect of increasing light intensity is that of flattening the bands (i.e. shifting upward the $\mathrm{E}_{\mathrm{F}}$ in a photoanode) hence the electrode open circuit shifts cathodic vs the reference, and for instance a current peak in the $\mathrm{CV}$ anodic scan is reached under less positive external biases. 


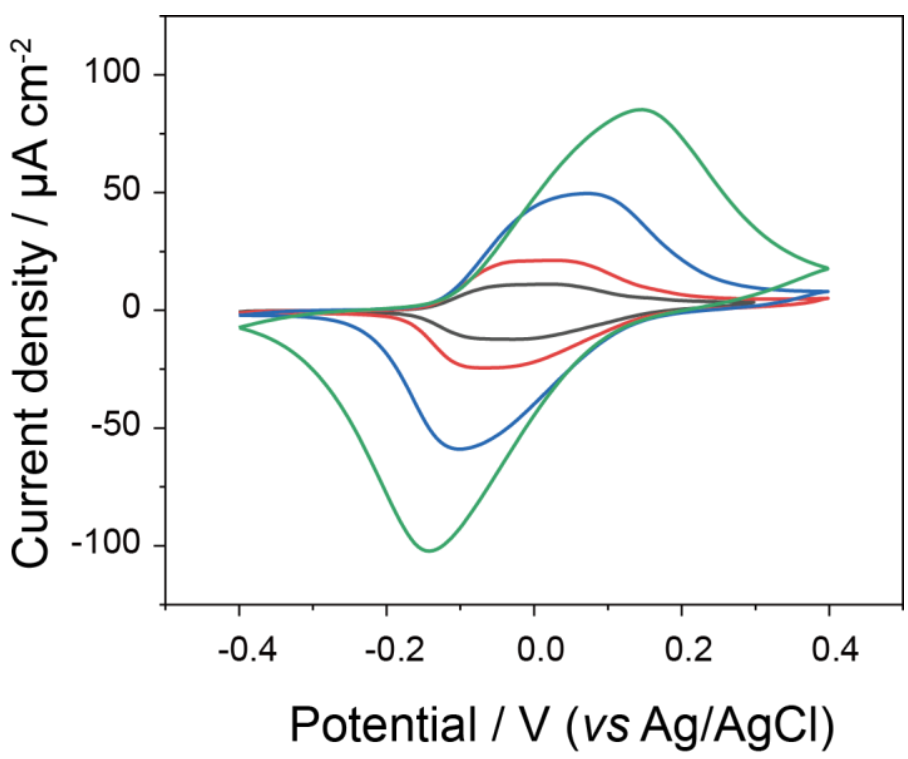

Figure S7. Representative CVs of a M-2 sample prepared on LD n-type $\mathrm{Si}(111)$ and recorded under a illuminaition intensity of $1.0 \mathrm{~mW} \mathrm{~cm}{ }^{-2}$. The voltage scan rate was $0.1,0.2,0.5$ and $1.0 \mathrm{~V} / \mathrm{s} . \Gamma$ is 2.34 $\times 10^{-10} \mathrm{~mol} \mathrm{~cm}^{-2}$. The electrolyte was aqueous $1.0 \mathrm{M} \mathrm{HClO}_{4}$. 


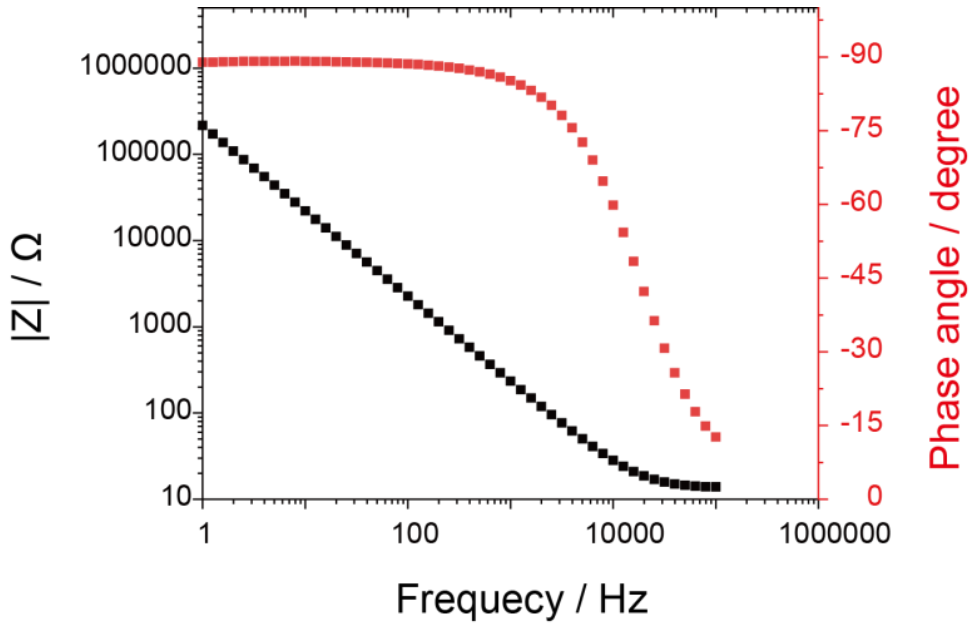

Figure S8. Electrochemical impedance spectroscopy (EIS) data for $\mathbf{M - 2}$ monolayers (n-type, Si(111), dark). The EIS data were acquired between $10^{5} \mathrm{~Hz}$ and $1 \mathrm{~Hz}$, at an applied working electrode DC potential of $-0.3 \mathrm{~V}$ versus $\mathrm{Ag} / \mathrm{AgCl}$, and with an $\mathrm{AC}$ perturbation of $15 \mathrm{mV}$. 


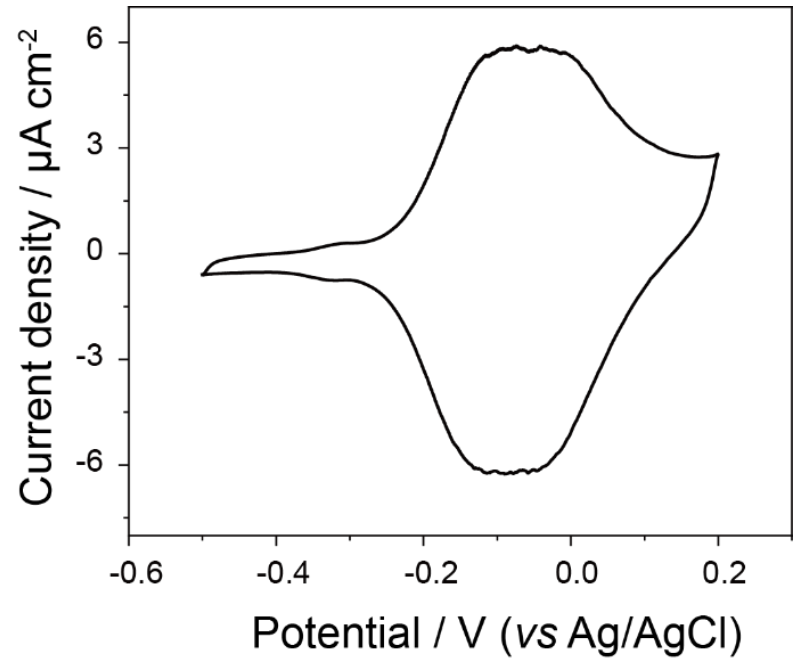

Figure S9. Representative CV of an M-2 sample prepared on a LD n-type $\mathrm{Si}(111)$ photoanode under a light intensity of $1.0 \mathrm{~mW} \mathrm{~cm}{ }^{-2}\left(1.0 \mathrm{M} \mathrm{HClO}_{4}\right)$. The scan rate is $0.1 \mathrm{~V} / \mathrm{s}$, and the ferrocene coverage $(\Gamma)$ is $1.07 \times 10^{-10} \mathrm{~mol} \mathrm{~cm}^{-2}$. The CuAAC click reaction was stopped after only 5 min of reaction time. 

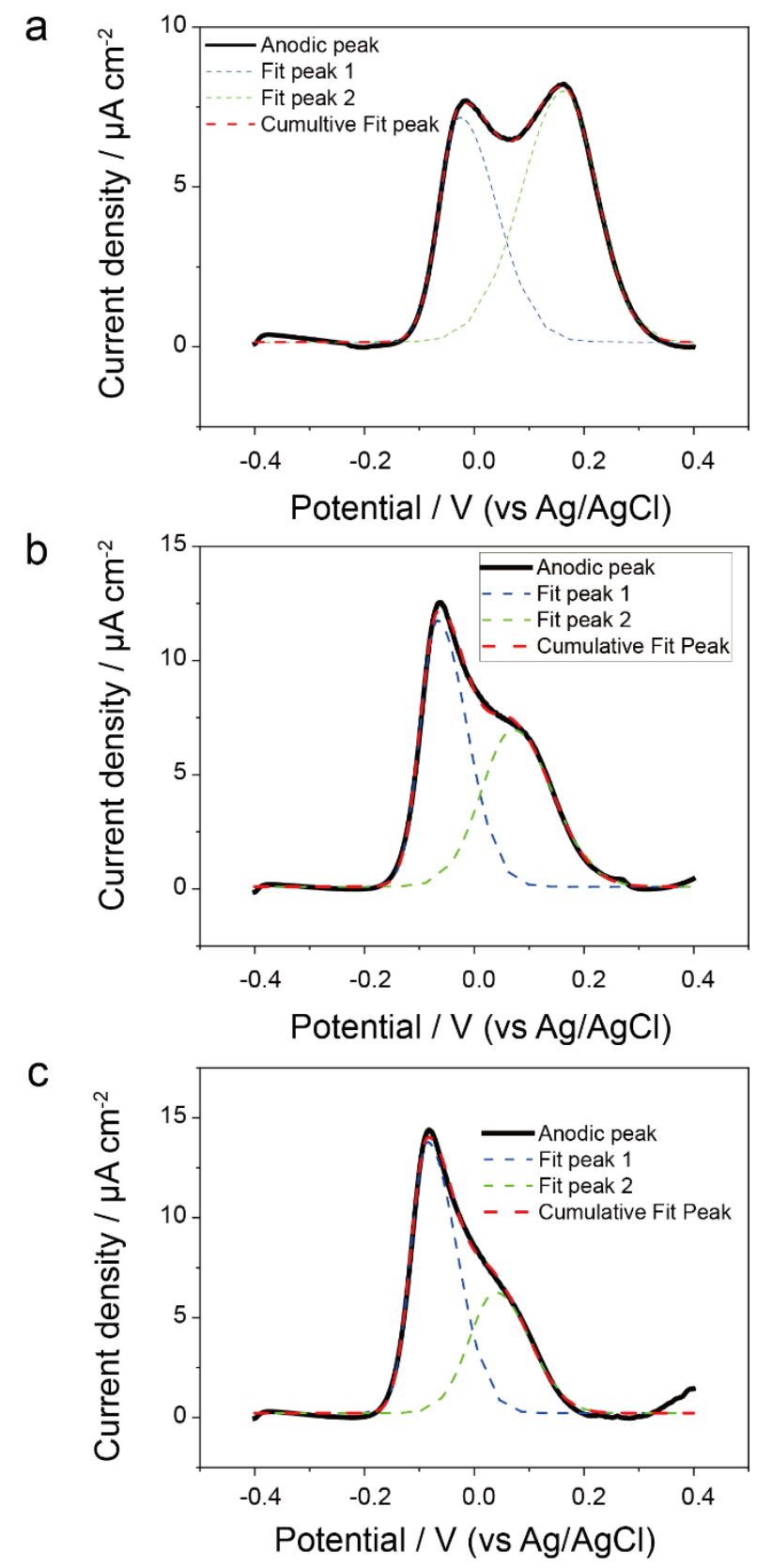

Figure S10. Deconvolution of the anodic peaks from representative CVs of M-2 monolayers prepared on n-type $\mathrm{LD}, \mathrm{Si}(111)$, recorded under variable light intensity. a) $1.0 \mathrm{~mW} \mathrm{~cm}{ }^{-2}$, cumulative coverage $=2.40 \times 10^{-10} \mathrm{~mol} \mathrm{~cm}{ }^{-2}$, fwhm of peak $1=122.2 \mathrm{mV}$, fwhm peak $2=161.7 \mathrm{mV}$; b) $2.9 \mathrm{~mW} \mathrm{~cm}^{-2}$, cumulative coverage $=2.43 \times 10^{-10} \mathrm{~mol} \mathrm{~cm}^{-2}$, fwhm of peak $1=99.7 \mathrm{mV}$, fwhm peak $2=152.2$ $\mathrm{mV}$; c) $4.7 \mathrm{~mW} \mathrm{~cm}{ }^{-2}$, cumulative coverage $=2.45 \times 10^{-10} \mathrm{~mol} \mathrm{~cm}^{-2}$, fwhm of peak $1=97.8 \mathrm{mV}$, fwhm peak $2=130.3 \mathrm{mV}$. Curve refinement was done using the bi-Gaussian peak function in Origin 9. 


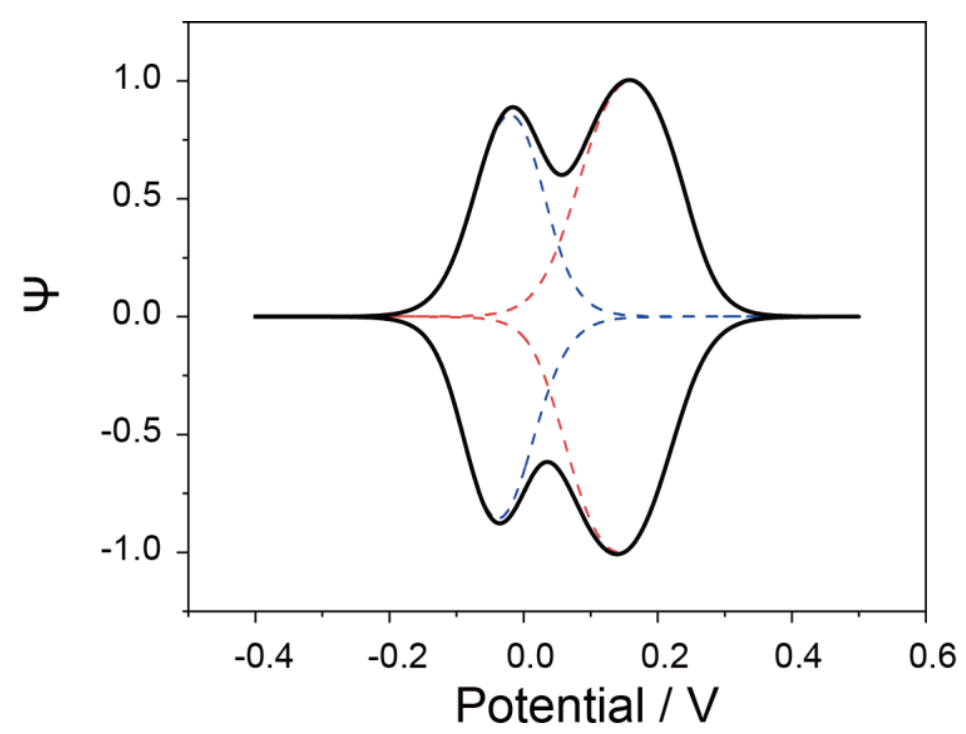

Figure S11. Simulation of the CV traces recorded at the lowest light intensity, demonstrating that the key feature of the experimental data, a $\sim 190 \mathrm{mV}$ peak-to-peak separation, can be accounted for as surface domains with a 1,000 fold difference in the dark leakage current $\left(1.0 \times 10^{-9}\right.$ A for the blue dashed trace, $1.1 \times 10^{-6} \mathrm{~A}$ for the red dashed trace). The self-interaction parameter, $G$, necessary to reproduce the experimental fwhm, is negative, indicating repulsive molecular interactions for ferrocenes in both domains $\left(-1.4\right.$, red trace; -0.6 , blue trace). Best fit parameters are $10 \mathrm{~s}^{-1}$ for the electron transfer rate constant, $750 \mu \mathrm{A}$ for photocurrent (both peaks), unity for the diode quality factor, and 0.5 for $\alpha$.

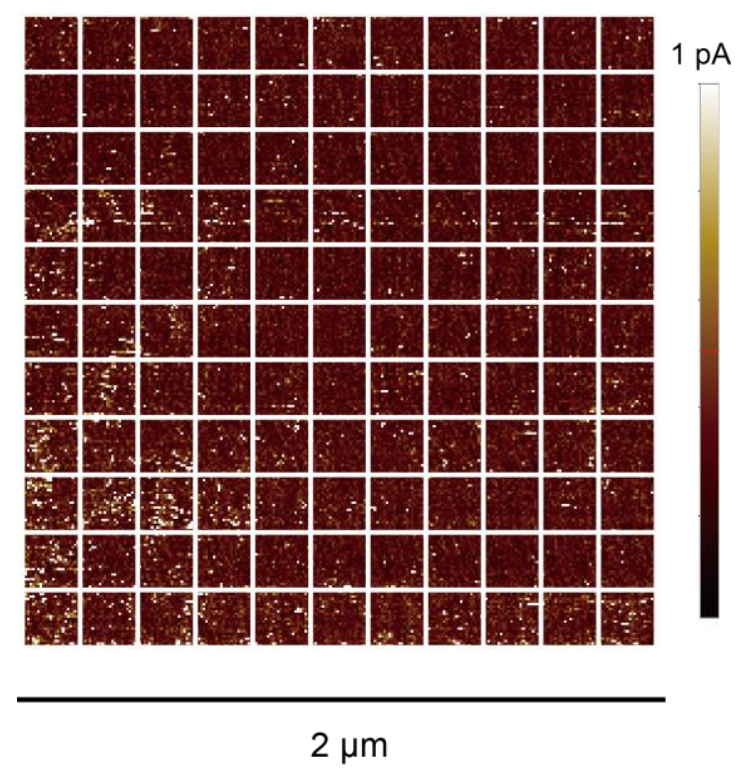

Figure S12. Representative AFM current map acquired at $0.1 \mathrm{~V}$. The sampling area is $2 \times 2 \mu \mathrm{m}$. Individual $\mathrm{I}-\mathrm{V}$ traces (from $-2.0 \mathrm{~V}$ to $+2.0 \mathrm{~V}$ ), shown in Figure 4 of the main text, were collected in the center of each square shown in figure. 


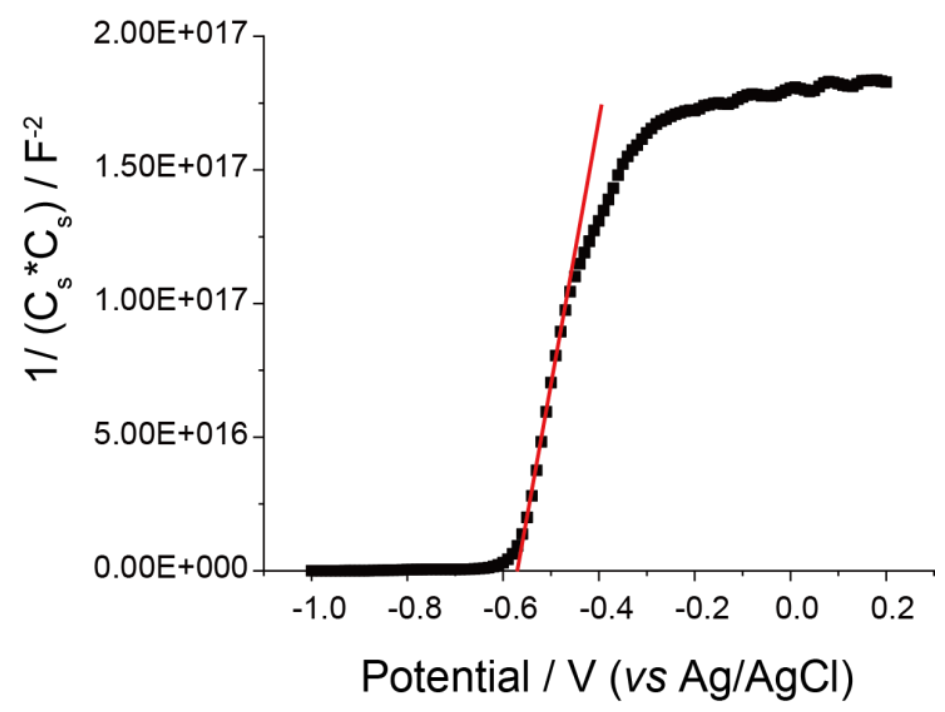

Figure S13. EIS Mott-Schottky (M-S) measurement of capacitance vs sample bias for an M-2 sample prepared on $\mathrm{LD}$ n-type $\mathrm{Si}(111)$. The experiments were run in dark, with the AC frequency set to $40,000 \mathrm{~Hz}$, the $\mathrm{AC}$ bias amplitude set to $15 \mathrm{mV}$. The electrolyte was $1.0 \mathrm{M}$ aqueous $\mathrm{HClO}_{4}$. 